Research Article

Human and Medical Genetics

\title{
Genetic variants in the fat mass and obesity-associated (FTO) gene confer risk for extreme obesity and modulate adiposity in a Brazilian population
}

Ana Carolina Proença da Fonseca ${ }^{1}$ (D), Bruna Marchesini ${ }^{1}$, Verônica Marques Zembrzuski ${ }^{1}$, Danielle Dutra Voigt $^{2}$, Vivianne Galante Ramos ${ }^{2}$, João Regis Ivar Carneiro ${ }^{3}$, José Firmino Nogueira $\mathrm{Neto}^{4}$, Giselda Maria Kalil de Cabello ${ }^{1}$ and Pedro Hernán Cabello ${ }^{1,2}$

${ }^{1}$ Instituto Oswaldo Cruz (FIOCRUZ), Laboratório de Genética Humana, Rio de Janeiro, RJ, Brazil.

${ }^{2}$ Universidade do Grande Rio, Laboratório de Genética Humana, Rio de Janeiro, RJ, Brazil.

${ }^{3}$ Universidade Federal do Rio de Janeiro, Hospital Universitário Clementino Fraga Filho, Rio de Janeiro, RJ, Brazil.

${ }^{4}$ Universidade do Estado do Rio de Janeiro, Departamento de Patologia, Rio de Janeiro, RJ, Brazil.

\begin{abstract}
Obesity is a major public health problem worldwide. It has a complex etiology, influenced by environmental and genetic factors. FTO has been recognized as an important genetic factor for obesity development. This study evaluated the contribution of FTO polymorphisms (rs9939609 and rs17817449) for extreme obesity in terms of the period of obesity onset, anthropometric, and biochemical parameters. The haplotype and the combined effects of FTO risk alleles on obesity susceptibility were evaluated. We investigated 169 normal-weight subjects (body mass index, BMI: 22.8 [21.0; 24.0$] \mathrm{kg} / \mathrm{m}^{2}$ ) and 123 extremely obese individuals (BMI: 47.6 [44.1;53.1] kg/m²). Genotyping was performed by real time PCR. Our results showed a strong association between FTO variants and extreme obesity. Carriers of the AT haplotype had an increased risk for extreme obesity. Gene scores suggested that the risk of developing extreme obesity was increased 1.37-fold per risk allele added. Both polymorphisms also influenced BMI and body weight. Additionally, rs17817449 influenced triglyceride levels. No effect of FTO variants on the period of obesity onset was found. In conclusion, the FTO polymorphisms showed a strong association with development of extreme phenotype of obesity and adiposity modulation in a Brazilian population.
\end{abstract}

Keywords: BMI, extreme obesity, FTO, haplotype, polymorphisms.

Received: September 3, 2018; Accepted: April 30, 2020.

\section{Introduction}

Obesity (body mass index, BMI $\geq 30 \mathrm{~kg} / \mathrm{m}^{2}$ ) is defined as an increase in body fat mass that is sufficient to cause adverse health effects. Over the last three decades, the prevalence of obesity has increased rapidly, affecting low-, middle-, and high-income countries. Recent data estimate that there are at least 600 million obese people in the world. In Brazil, 20\% of the population was obese in 2015 (WHO, 2018). Epidemiological studies have shown that subjects with severe obesity and morbid obesity (BMI $\geq 35$ $\mathrm{kg} / \mathrm{m}^{2}$ and $\mathrm{BMI} \geq 40 \mathrm{~kg} / \mathrm{m}^{2}$, respectively) have a substantial increase in the risk of comorbidities and mortality. Furthermore, this elevated BMI was associated with 6.5-13.7 years lost in life expectancy (Kitahara et al., 2014). The

Send correspondence to Ana Carolina Proença da Fonseca. Laboratório de Genética Humana, Instituto Oswaldo Cruz, Fundação Oswaldo Cruz (FIOCRUZ), Pavilhão Leônidas Deane, Avenida Brasil 4365, 21040-360 Rio de Janeiro, RJ, Brazil. E-mail: ana.proenca@ioc.fiocruz.br. prevalence of severe obesity in women is three times higher than men in Brazil. There are 6.7 million women with this disease, whereas only 2.2 million men. Currently, the prevalence of morbid obesity is nearly $1.1 \%$ in the world (NCD Risk Factor Collaboration, 2016).

Obesity is a multifactorial disease, influenced by environmental and genetic factors (Grundy, 1998). Researchers have been making a continuous effort to identify genes and variants that predispose individuals to common forms of obesity (Rankinen et al., 2006; Fonseca et al., 2017). Nowadays, over 291 loci were found associated with obesity, involved in different biological pathways, including adipocyte differentiation, lipid metabolism, thermogenesis, and food intake control (Wu et al., 2018). Among the genes, the association of fat mass and obesity-associated gene (FTO) with obesity susceptibility was confirmed. Different groups identified that common variants in the first intron of FTO are associated with an increased body fat mass in humans (Dina et al., 2007; Frayling et al., 2007; Scuteri et al., 2007). Besides the associa- 
tion with obesity, $F T O$ variants have also been correlated to body composition and obesity-related traits (Scuteri et al., 2007; Shabana and Hasnain, 2015).

FTO encodes a Fe(II)- and 2-oxoglutarate (OG)-dependent nucleic acid demethylase that is localized in the cell nucleus. The highest levels of FTO mRNA are found in the hypothalamus, particularly in the arcuate nucleus. This area of the brain has an important role in controlling food intake, which suggests that FTO may act in the management of energy balance (Gerken et al., 2007). Located in chromosome 16, the FTO gene spans for more than $400 \mathrm{~kb}$ and has nine exons. Despite the large size of this gene, most of the variations that were associated with obesity are found in the first intron (Loos and Bouchard, 2008).

The influence of $F T O$ variants on the risk of obesity is consistent in Caucasian studies (Dina et al., 2007). However, apparently it is not relevant in African Americans, Chinese Han, and Native Oceanic populations (Ohashi et al., 2007; Scuteri et al., 2007; Li et al., 2008). In Brazil, few studies have analyzed the relationship between FTO rs9939609 polymorphism and obesity susceptibility. Reuter et al. (2016) studied the association between this polymorphism and overweight/obesity risk in a sample of youths from the South of Brazil. They observed that the rs9939609 was associated with BMI and waist circumference. Pereira et al. (2016) have performed a similar study with children; however, they did not find this association. Ramos et al. (2012) investigated the contribution of this polymorphism in morbid obesity risk. They analyzed 126 morbidly obese individuals and 113 controls from Minas Gerais, in the southeastern region of Brazil. Their result suggested that presence of the rs9939609(A) allele increased the risk for obesity. These divergent results may be explained by differences in the inclusion criteria of participants, as well as environmental and genetic backgrounds. Therefore, more studies are needed to elucidate the association of FTO rs9939609 and obesity development in Brazil. In addition, we also selected the FTO rs 17817449 polymorphism for analysis. To date, no study was performed with this polymorphism in the Brazilian population.

The aim of our study was to evaluate the role of the FTO rs9939609 and rs 17817449 polymorphisms in the risk of extreme obesity, period of obesity onset, and in relation to anthropometric and biochemical parameters. We also investigated the influence of haplotype and the combined effect of FTO variants on extreme obesity development.

\section{Materials and Methods}

\section{Subjects}

This cross-sectional case-control study comprised 292 unrelated individuals (68.2\% female and $31.8 \%$ male), aged 18 to 65 years (median, 33.0 [26.0; 43.0]), from Rio de Janeiro, southeast of Brazil. The participants were divided into two groups according to BMI (calculated by dividing weight [kilograms] by the height squared [meters]). The exclusion criteria were pregnancy, lactation, and the use of medication to lose or gain weight. The first group included 123 subjects with extreme obesity (BMI $\geq 40.0 \mathrm{~kg} / \mathrm{m}^{2}$ ) recruited from a non-governmental organization called to Self-Esteem and Citizenship Rescue Group for the Obese (in Portuguese, "Grupo de Resgate à Autoestima e Cidadania do Obeso"). These patients were candidates for bariatric surgery. The period of obesity onset was self reported. The second group included 169 individuals with normal weight $\left(18.5 \leq \mathrm{BMI} \leq 24.9 \mathrm{~kg} / \mathrm{m}^{2}\right)$ that were volunteers in public hospitals in the same city. The study protocol was performed according to the Declaration of Helsinki (1964). All participants provided written consent prior to their inclusion in this study and the protocol was approved by Ethics Committee of the Oswaldo Cruz Foundation.

\section{Anthropometric measurements}

Height, weight, and waist and hip circumference were measured by a trained person. Waist circumference was measured at the midpoint between the iliac crest and the last costal arch. Hip circumference was measured at the level of the greater trochanters. BMI and waist to hip ratio (WHR) were then calculated for each subject.

\section{Biochemistry}

Serum samples were collected and clinical variables were measured after an overnight fast. Glucose, total cholesterol (TC), HDL-cholesterol (HDL-c), and triglyceride (TG) were measured by the oxidase-peroxidase method (BioSystems). LDL-cholesterol (LDL-c) was calculated by the Friedewald formula (LDL-c $=$ TC $-\mathrm{HDL}-\mathrm{c}-\mathrm{TG} / 5$ ). Individuals using medication for these biochemical parameters had their levels excluded from statistical analysis.

\section{Demographic characteristics}

Practice of physical activity was categorized as "yes" or "no" according to the participant's report of the last month. The classification of the Demographic Census conducted by the Brazilian Institute of Geography and Statistics was used to categorize the race/skin color of participants (white, brown, black, and others [yellow or indigenous]). All information was self reported and collected using standardized questionnaires.

\section{Single nucleotide polymorphism (SNP) genotyping}

Genomic DNA was extracted from peripheral white blood cells using a commercial DNA extraction kit (QIAamp Blood Kit, Qiagen, Valencia, CA, USA). FTO rs9939609 and rs17817449 polymorphisms were genotyped by real time PCR using TaqMan ${ }^{\circledR}$ assays (ThermoFisher, Carlsbad, CA, USA). Reactions were performed in $10 \mu \mathrm{L}$ volumes, including 2-10 ng of DNA, Universal Master Mix 1X, and TaqMan Genotyping Assay 1X specific for each polymorphism studied. Amplification was carried out 
in a StepOne ${ }^{\circledR}$ Plus Real Time PCR System (ThermoFisher) using the number of cycles and temperatures according the manufacturer's recommendations. All plates included a negative control (all components excluding DNA).

\section{Statistical analysis}

Normality of continuous variables was tested by Kolmogorov-Smirnov and Shapiro Wilk tests. All continuous parameters had a non-normal distribution. Differences of clinical, biochemical, and anthropometric parameters between case and control groups were compared by Mann Whitney and $\chi^{2}$ tests.

Genotype and allele frequencies were estimated by gene counting. Hardy-Weinberg equilibrium (HWE) was tested for each polymorphism using the $\chi^{2}$ test. Logistic regression was carried out in order to analyze the association between $F T O$ polymorphisms and the risk for extreme obesity. All analyses were adjusted for age and gender (model 1) and then for race/skin color and physical activity practice (model 2). Anthropometric and biochemical variables were log-transformed before linear regression. All linear regression analyses were adjusted by model 1 and 2 . We also included BMI as covariate, excepted for BMI and body weight. Both logistic and linear regressions were carried out in additive, recessive, and dominant models.

Haplotypes were obtained and their associations with obesity were verified by $\chi^{2}$ test (OR was calculated). A pairwise linkage disequilibrium analysis between rs9939609 and rs17817449 polymorphisms was carried out. Furthermore, gene score + was used to calculate the combined risk alleles. Individuals were encoded as 0 (homozygous protective), 1 (heterozygous), and 2 (homozygous risk) for each variant studied (Shabana and Hasnain, 2015; Shabana et al., 2016). Then, the number of risk alleles was calculated from the sum of the codes for both rs9939609 and rs17817449 polymorphisms. The mean of risk alleles was compared between the groups using Student's $t$-test. Logistic regression was also used to calculate the extreme obesity risk per unit allele increased. Finally, period of obesity onset was obtained from individuals with extreme obesity phenotype. The Mann-Whitney test was used to calculate BMI differences between subjects with early and late-onset obesity. Finally, the association of FTO polymorphisms with the period of obesity onset was tested using logistic regression. Since different polymorphisms were analyzed, a Bonferroni's correction was used and a $p$-value of 0.025 was applied as a significant cutoff. All data analyses were performed using the SPSS statistical package, Haploview, and PHASE.

Sample size calculation was performed using an iterative process to compute the minimum number of individuals necessary to test the difference between two groups of a qualitative variable according to Zar (1999). In this study, rs9939609 and rs 17817449 polymorphisms were analyzed, and thus a conservative and convenience sample was chosen $(80 \%$ of statistic power).

\section{Results}

\section{Basic characteristics of the study population}

Clinical characteristics from the 292 subjects, stratified into case and controls by BMI status, are shown in Table 1. As expected, anthropometric and biochemical data were significantly increased in individuals with extreme obesity when compared to the control group. Exceptions were in HDL-cholesterol and height, in which the control individuals had higher values. We also observed that the control group practiced more physical activities and exhibited a higher proportion of subjects with white race/skin color.

\section{FTO frequencies and Hardy-Weinberg equilibrium}

All subjects were genotyped for FTO rs9939609 and rs 17817449 variants. Both were polymorphic in our sample. The details about the genotypic and allelic frequencies are presented in Table 2. Genotypes of rs9939609 and rs17817449 polymorphisms were in HWE $(p>0.05)$ for both case and control groups.

\section{Influence of FTO variants on extreme obesity risk}

The distribution of genotypes and alleles for rs9939609 and rs17817449 polymorphisms was compared between case and control groups (Table 2). Our results showed that the genotypic and allelic frequencies of both polymorphisms differed significantly between the groups. The frequency of the rs9939609(AA) genotype was significantly higher in the extremely obese group when compared to the control group. Allelic analysis showed that the prevalence of the rs9939609(A) allele was higher in subjects with extreme obesity ( 0.54 vs. $0.41 ; p=0.003$ ). Individuals carrying the rs 9939609 (A) allele had a 1.7 times higher risk for developing this phenotype.

The frequency of the rs 17817449 (TT) genotype was higher in the case than in the control group. Furthermore, subjects carrying the TT genotype had a 4.5-fold increased risk for extreme obesity. In addition, carriers of at least one rs17817449(T) allele were 1.98 times more likely to develop this extreme phenotype. All these associations remained after adjusting for covariates (model 2).

\section{Haplotype and linkage disequilibrium}

Haplotype group analyses were performed using FTO rs9939609 and rs17817449. In the whole sample, the most common haplotypes were TG (50\%) and AT (39.5\%). The distribution of haplotypes between the case and control groups is shown in Table 3. Our results demonstrated that carriers of the AT haplotype had a 1.87-fold increased risk for extreme obesity development when compared to individuals with TG haplotype. 
Table 1 - Characteristics of study population.

\begin{tabular}{|c|c|c|c|c|c|c|c|}
\hline Variables & $\mathrm{N}$ & All & $\mathrm{n}$ & Control & $\mathrm{n}$ & Case & $p$ \\
\hline Age (years) & 292 & $33(26 ; 43)$ & 169 & $29(24 ; 38)$ & 123 & $39(31 ; 49)$ & $<0.001$ \\
\hline Gender (female/male) & 292 & $199 / 93$ & 169 & $100 / 69$ & 123 & $99 / 24$ & $<0.001$ \\
\hline \multicolumn{8}{|l|}{ Race/ Skin color } \\
\hline White & 291 & $163(56.0)$ & 169 & $114(67.5)$ & 122 & $49(40.2)$ & $<0.001$ \\
\hline Brown & & $84(28.9)$ & & $44(23)$ & & $40(32.8)$ & \\
\hline Black & & $42(14.4)$ & & $11(6.5)$ & & $31(25.4)$ & \\
\hline Others & & $2(0.7)$ & & $0(0)$ & & $2(1.6)$ & \\
\hline \multicolumn{8}{|l|}{ Physical Activity Practice } \\
\hline Yes & 289 & $116(40.1)$ & 169 & $88(52.1)$ & 120 & $28(23.3)$ & $<0.001$ \\
\hline No & & $173(59.9)$ & & $81(47.9)$ & & $92(76.7)$ & \\
\hline Weight (kg) & 292 & $74.1(61.3 ; 126.2)$ & 169 & $63.0(57.0 ; 70.3)$ & 123 & $131.5(115.5 ; 146.5)$ & $<0.001$ \\
\hline Height (m) & 292 & $1.65(1.60 ; 1.73)$ & 169 & $1.69(1.62 ; 1.74)$ & 123 & $1.62(1.58 ; 1.69)$ & $<0.001$ \\
\hline BMI $\left(\mathrm{kg} / \mathrm{m}^{2}\right)$ & 292 & $24.6(22.4 ; 46.61)$ & 169 & $22.8(21.0 ; 24.0)$ & 123 & $47.6(44.1 ; 53.1)$ & $<0.001$ \\
\hline Waist circumference $(\mathrm{cm})$ & 292 & $98.0(83.0 ; 134.0)$ & 169 & $84.0(76.0 ; 91.0)$ & 122 & $138.3(128.0 ; 148.3)$ & $<0.001$ \\
\hline Hip circumference (cm) & 292 & $103.0(92.5 ; 141.0)$ & 169 & $95.0(85.3 ; 100.3)$ & 122 & $144.0(134.0 ; 154.3)$ & $<0.001$ \\
\hline WHR & 292 & $0.92(0.83 ; 1.01)$ & 169 & $0.86(0.80 ; 1.04)$ & 122 & $0.97(0.91 ; 1.01)$ & $<0.001$ \\
\hline Glucose (mg/dL) & 259 & $92.0(86.0 ; 1025)$ & 163 & $88.0(84.0 ; 95.0)$ & 96 & $103.0(94.0 ; 115.8)$ & $<0.001$ \\
\hline Total cholesterol $(\mathrm{mg} / \mathrm{dL})$ & 259 & $182.0(159.0 ; 2090)$ & 163 & $178.0(156.0 ; 198.0)$ & 96 & $192.0(168.0 ; 220.8)$ & 0.003 \\
\hline HDL cholesterol (mg/dL) & 259 & $52.0(44.0 ; 63.0)$ & 163 & $58.0(47.0 ; 68.0)$ & 96 & $47.0(41.0 ; 53.8)$ & $<0.001$ \\
\hline LDL cholesterol (mg/dL) & 255 & $108.0(88.0 ; 1270)$ & 162 & $102.0(86.8 ; 122.3)$ & 93 & $116.0(95.5 ; 137.0)$ & 0.002 \\
\hline Triglycerides (mg/dL) & 259 & $88.0(68.0 ; 131.0)$ & 163 & $76.0(61.0 ; 102.0)$ & 96 & $128.0(93.8 ; 185.0)$ & $<0.001$ \\
\hline
\end{tabular}

Data are presented as medians values (interquartile range) for continuous traits and $\mathrm{n}(\%)$ for categorical traits. Data were analyzed by Mann-Whitney Test (for non-normally distributed variables), or $\chi^{2}$ test (for categorical variables).

BMI, Body Mass Index; WHR, Waist-to-Hip Ratio; HDL cholesterol, High Density Lipoprotein-cholesterol; LDL cholesterol, Low Density Lipoprotein-cholesterol.

$p$-value for difference between case and control groups.

The polymorphisms studied are located in the first intron of $F T O$, and the distance from one another is about $7.2 \mathrm{~kb}$. Our analysis demonstrated that $F T O$ rs 9939609 and rs 17817449 are in linkage disequilibrium ( $D^{\prime}=0.78 ; r^{2}=$ $0.583 ; \mathrm{LOD}=52.63$ ).

\section{Additive effects of FTO risk alleles on obesity}

The combined effect of risk alleles was performed in order to study their influence on extreme obesity development. Our results showed that the average number of risk alleles was different between the groups (cases $=2.05 \pm$ 1.34; controls $=1.52 \pm 1.34 ; p=0.001)$. Furthermore, the risk of being obese increased 1.37-fold for each risk allele added $(\mathrm{OR}=1.37[1.14-1.66] ; p=0.001)$.

\section{Association of FTO variants with biochemical and anthropometric parameters}

The influence of both FTO polymorphisms on biochemical and anthropometric measurements was analyzed by linear regression. FTO rs9939609 was associated with body weight in the additive model. Moreover, it was associated with BMI in the additive, dominant, and recessive models (Table 4). However, the association with BMI in the recessive model did not remain after correcting for covariates (model 2). FTO rs17817449 was associated with body weight in the additive and recessive models. This variant was also related with BMI in the additive, dominant, and recessive models. Furthermore, FTO rs 17817449 influenced the triglycerides levels in the recessive model (Table 5). Our results indicated no significant effects of rs9939609 and rs 17817449 variants on fasting glucose levels, total cholesterol, HDL-cholesterol, LDL-cholesterol, WHR, and waist and hip circumferences.

\section{Association of FTO variants with onset of obesity}

We divided the case group according to the period of obesity onset, stratifying in early-onset obesity (childhood and adolescence) and late-onset obesity (adulthood). Of the 123 individuals with extreme obesity, 70 subjects developed obesity during childhood/adolescence (56.9\%), and 53 individuals developed obesity during adulthood (43.1\%). Our results showed no relation between BMI and period of obesity onset, in which both early-onset (BMI = $\left.48.84[44.65 ; 55.05] \mathrm{kg} / \mathrm{m}^{2}\right)$ and late-onset $(\mathrm{BMI}=46.92$ $\left.[43.11 ; 52.87] \mathrm{kg} / \mathrm{m}^{2}\right)$ had similar median values $(p=$ 0.376 ). We also analyzed whether those polymorphisms in- 
Table 2 - Genotypic and allelic frequencies of FTO rs9939609 and rs17817449 polymorphisms.

\begin{tabular}{|c|c|c|c|c|c|c|}
\hline \multirow[t]{2}{*}{ FTO polymorphisms } & \multirow{2}{*}{$\begin{array}{c}\text { Control } \\
\mathrm{n}=169(\%)\end{array}$} & \multirow{2}{*}{$\begin{array}{c}\text { Case } \\
\mathrm{n}=123(\%)\end{array}$} & \multicolumn{2}{|c|}{ Model 1} & \multicolumn{2}{|c|}{ Model 2} \\
\hline & & & OR $(95 \% \mathrm{CI})$ & $P$ & OR $(95 \% \mathrm{CI})$ & $p$ \\
\hline \multicolumn{7}{|l|}{ rs9939609 } \\
\hline \multicolumn{7}{|l|}{ Genotype } \\
\hline $\mathrm{TT}$ & $64(37.9)$ & $27(22.0)$ & 1.00 (Ref.) & - & 1.00 (Ref.) & - \\
\hline TA & $72(42.6)$ & $59(48.0)$ & $1.97(1.06-3.66)$ & 0.032 & $1.90(0.99-3.66)$ & 0.054 \\
\hline $\mathrm{AA}$ & $33(19.5)$ & $37(30.1)$ & $2.88(1.41-5.89)$ & 0.004 & $2.51(1.17-5.35)$ & 0.017 \\
\hline \multicolumn{7}{|l|}{ Dominant Model } \\
\hline TT & $64(37.9)$ & $27(22.0)$ & 1.00 (Ref.) & - & 1.00 (Ref.) & - \\
\hline $\mathrm{TA}+\mathrm{AA}$ & $105(62.1)$ & $96(78.0)$ & $2.25(1.26-4.01)$ & 0.006 & $2.09(1.14-3.84)$ & 0.016 \\
\hline \multicolumn{7}{|l|}{ Recessive Model } \\
\hline $\mathrm{TT}+\mathrm{TA}$ & $136(80.5)$ & $86(69.9)$ & 1.00 (Ref.) & - & 1.00 (Ref.) & - \\
\hline $\mathrm{AA}$ & $33(19.5)$ & $37(30.1)$ & $1.91(1.05-3.48)$ & 0.035 & $1.74(0.90-3.33)$ & 0.097 \\
\hline \multicolumn{7}{|l|}{ Allele } \\
\hline $\mathrm{T}$ & $200(59.2)$ & $113(45.9)$ & 1.00 (Ref.) & - & 1.00 (Ref.) & - \\
\hline A & $138(40.8)$ & $133(54.1)$ & $1.70(1.19-2.43)$ & 0.003 & $1.60(1.10-2.33)$ & 0.014 \\
\hline \multicolumn{7}{|l|}{ rs17817449 } \\
\hline \multicolumn{7}{|l|}{ Genotype } \\
\hline $\mathrm{G} / \mathrm{G}$ & $64(37.9)$ & $33(26.8)$ & 1.00 (Ref.) & - & 1.00 (Ref.) & - \\
\hline $\mathrm{G} / \mathrm{T}$ & $91(53.8)$ & $60(48.8)$ & $1.41(0.78-2.52)$ & 0.365 & $1.21(0.65-2.26)$ & 0.531 \\
\hline $\mathrm{T} / \mathrm{T}$ & $14(8.3)$ & $30(24.4)$ & $4.74(2.04-11.01)$ & 0.0003 & $3.89(1.56-9.38)$ & 0.003 \\
\hline \multicolumn{7}{|l|}{ Dominant Model } \\
\hline GG & $64(37.9)$ & $33(26.8)$ & 1.00 (Ref.) & - & 1.00 (Ref.) & - \\
\hline $\mathrm{GT}+\mathrm{TT}$ & $105(62.1)$ & $90(73.2)$ & $1.83(1.05-3.19)$ & 0.034 & $1.57(0.87-2.82)$ & 0.130 \\
\hline \multicolumn{7}{|l|}{ Recessive Model } \\
\hline $\mathrm{GG}+\mathrm{GT}$ & $155(91.7)$ & $93(75.6)$ & 1.00 (Ref.) & - & 1.00 (Ref.) & - \\
\hline $\mathrm{TT}$ & $14(8.3)$ & $30(24.4)$ & $3.83(1.80-8.17)$ & 0.001 & $3.41(1.50-7.74)$ & 0.003 \\
\hline \multicolumn{7}{|l|}{ Allele } \\
\hline G & $219(64.8)$ & $126(51.2)$ & 1.00 (Ref.) & - & 1.00 (Ref.) & - \\
\hline $\mathrm{T}$ & $119(35.2)$ & $120(48.8)$ & $1.98(1.33-2.96)$ & 0.001 & $1.75(1.15-2.67)$ & 0.009 \\
\hline
\end{tabular}

Model 1 adjusted for gender and age.

Model 2 adjusted for gender, age, race/skin color and physical activity practice.

Table 3 - Association of FTO haplotypes with obesity susceptibility.

\begin{tabular}{lcccc}
\hline Haplotype & Control & Extremely obese & OR $(95 \% \mathrm{CI})$ & $p$ \\
\cline { 2 - 4 } & $\mathrm{n}=169(\%)$ & $\mathrm{n}=123(\%)$ & & \\
\hline $\mathrm{T} / \mathrm{G}$ & $187(55.3)$ & $110(44.7)$ & 1.00 (Ref.) & - \\
$\mathrm{T} / \mathrm{T}$ & $13(3.8)$ & $3(1.2)$ & $0.44(0.14-1.40)$ & 0.156 \\
$\mathrm{~A} / \mathrm{G}$ & $32(9.5)$ & $16(6.5)$ & $0.86(0.46-1.62)$ & 0.639 \\
$\mathrm{~A} / \mathrm{T}$ & $106(31.4)$ & $117(47.6)$ & $1.87(1.32-2.66)$ & $\mathbf{0 . 0 0 0 5}$ \\
\hline
\end{tabular}

fluence the period of obesity onset. However, no association was found for both variants (data not shown).

\section{Discussion}

Obesity is a complex phenotype influenced by genetic and environmental factors. In the last decades, indi- viduals have changed the lifestyle, resulting in energy imbalance caused by excessive food intake and diminished physical activity. Regarding genetic factors, the FTO gene has been recognized as one of the main contributors to polygenic obesity. However, the influence of FTO variants has been controversial among different populations (Ohashi et al., 2007; Scuteri et al., 2007; Li et al., 2008; Ramos et al., 2012; Pereira et al., 2016). Moreover, there are only few studies associating FTO variants and extreme obesity, since sample selection is difficult and requires considerable effort. The strategy of using an extreme phenotype sample probably increases the power for detecting genetic associations in a median sample size (Price et al., 2008; Castro et al., 2015).

In this study, we observed a strong association between the FTO rs9939609 and rs17817449 polymorphisms 

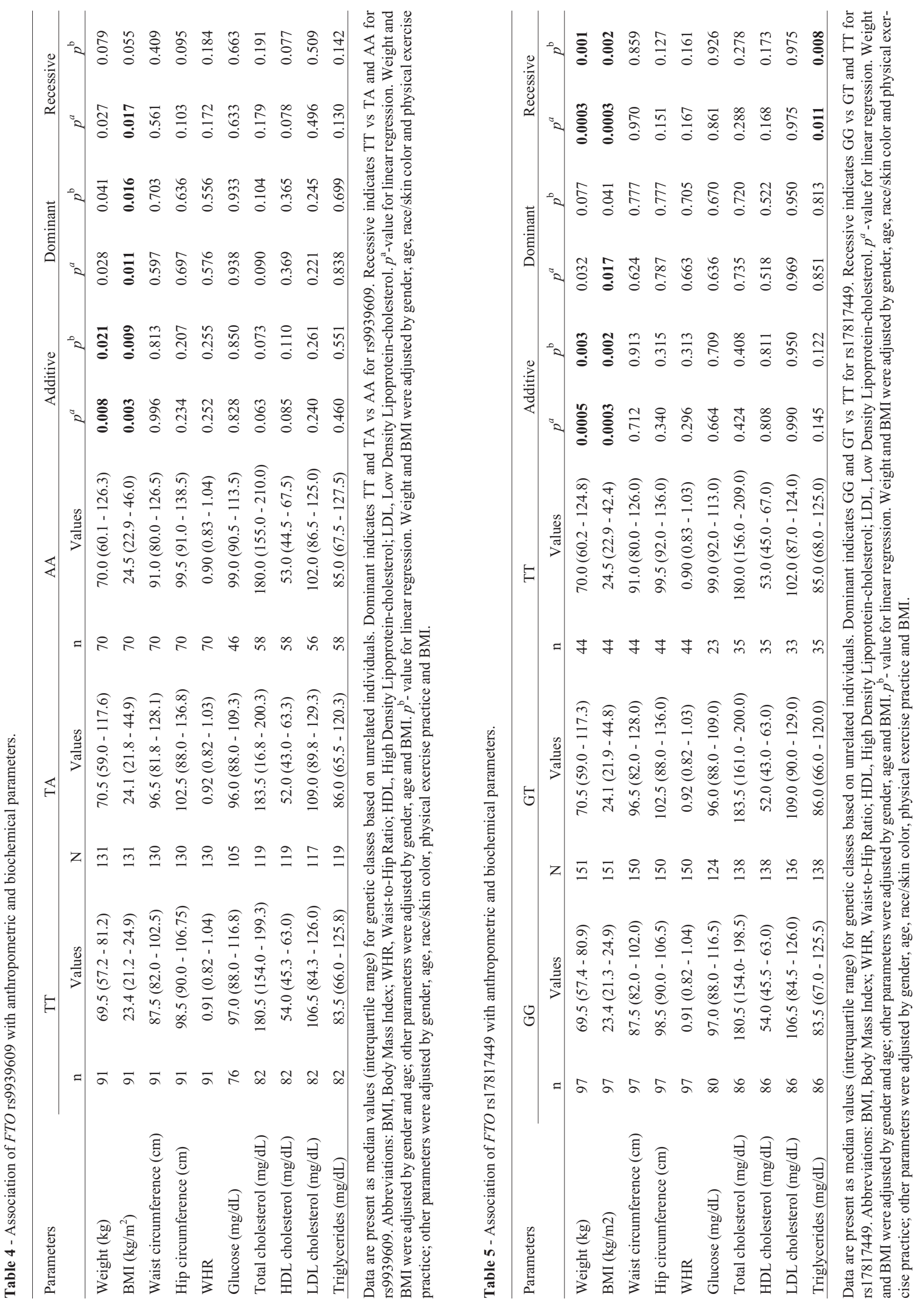
and risk for extreme obesity in a Brazilian population sample. These polymorphisms are located in the first intron of FTO, which is a region that has been consistently associated with adiposity in humans (Dina et al., 2007; Frayling et al., 2007; Scuteri et al., 2007). Interestingly, the rs9939609 and rs17817449 polymorphisms were associated with extreme obesity in different populations (Price $e t$ al., 2008; Villalobos-Comparán et al., 2008). Price et al. (2008) found that the rs9939609(A) and rs17817449(G) alleles were risk factors for extreme obesity in women from Spain. However, González et al. (2012) reported that only rs17817449(T) was associated with extreme obesity in individuals from Western Spain when a single analysis was performed. Ramos et al. (2012) observed that presence of the rs9939609(A) allele increased the risk for morbid obesity in a Brazilian population. Furthermore, VillalobosComparán et al. (2008) reported that both FTO variants were in strong linkage disequilibrium and were associated with extreme obesity in Mexican mestizos subjects, which was corroborated by our results.

Different studies have analyzed the contribution of single nucleotide polymorphisms for obesity risk. However, common forms of obesity have a complex etiology and could be explained by combined effects of variants located in the same or different genes (Shabana and Hasnain, 2015). Our study showed that the mean values of FTO risk alleles were higher in the case group. We also found that the risk of developing extreme obesity increased for each risk allele added. Only few previous studies had performed such an analysis. Nevertheless, it is a robust approach when the genetic study has a small or median sample size (Rouskas et al., 2012; Lazopoulou et al., 2015; Shabana and Hasnain, 2015). Shabana and Hasnain (2015) performed this analysis using the rs 9939609 polymorphism and other different variants in the same gene. Interestingly, they reported that the mean of risk alleles was elevated in an obese group from Pakistan. Our results are in accordance with earlier studies that reported that the homozygote risk variants for both polymorphisms are strongly associated with obesity susceptibility (Price et al., 2008; Villalobos-Comparán et al., 2008).

We also tested the influence of these polymorphisms on anthropometric and biochemical parameters. Our results showed that rs9939609 and rs17817449 were associated with BMI and body weight. Furthermore, the rs 17817449 polymorphism was also associated with triglycerides levels. A variety of studies has investigated the effect of rs9939609 and rs17817449 variants on metabolic and anthropometric measurements, and these reported divergent results (Sentinelli et al., 2012; Lazopoulou et al., 2015; Shabana et al., 2016). These different results may be explained by the effect of these two FTO variants that depend on environmental factors and ethnicity of the population.

Additionally, we investigated the influence of FTO variants on the period of obesity onset. No association was found in our population. Previous studies have reported that the rs9939609 polymorphism was associated with body weight according to age. Sentinelli et al. (2012) suggested that individuals carrying the rs9939609(A) risk allele had an increased body size earlier in life. Another study investigated the longitudinal pattern of the relationship between the rs9939609 variant and BMI during childhood, adolescence, and adulthood. This polymorphism was strongly associated with increased BMI during childhood, adolescence, and early adulthood (Hardy et al., 2010). Reasons for the discrepancies in these results may be explained by a different methodology design, since we have performed a cross-sectional study. Furthermore, the period of obesity onset was self reported in our study, whereas Sentinelli et al. (2012) used the age of individuals at the moment of sample collection.

The role of FTO protein in obesity is not completely elucidated. However, high levels of FTO mRNA were detected in a hypothalamus region that is involved in energy homeostasis. Animal studies suggested that Fto expression is regulated by feeding and fasting (Gerken et al., 2007). Church et al. (2010) also reported that loss of function or expression of $F$ to is associated with an increased energy expenditure and a lean phenotype; otherwise, the overexpression induced an increased food intake and resulted in obesity.

Even though the two polymorphisms are not located in an encoding region, they may exert functional effects through altered levels of FTO mRNA (Gerken et al., 2007), or they are in linkage disequilibrium with another causative genetic variant (Prakash et al., 2016). Additionally it has been suggested that the polymorphisms located in noncoding sequences (intron 1 and 2) within FTO interact with the promotor region of another gene in the neighborhood, called IRX3. Consistent with this, FTO polymorphisms associated with obesity alter the expression of IRX3 in human brains, which is related with regulation of body mass and composition (Smemo et al., 2014). Therefore, our results suggest that FTO rs9939609 and rs17817449 are risk factors for obesity; however, more functional studies are required to confirm these results.

\section{Conclusion}

In this study, we investigated the association between FTO polymorphisms (rs9939609 and rs17817449) and the risk for extreme obesity development. We identified that FTO rs9939609 and rs17817449 polymorphisms have a strong association with extreme obesity and adiposity modulation in a Brazilian population sample.

\section{Acknowledgments}

The authors thank Rosimere Lima for her excellent work with patients in GRACO. We also thank all the patients who kindly agreed to participate in this study. This 
work was funded by Oswaldo Cruz Foundation (FIOCRUZ, Brazil), National Counsel of Technological and Scientific Development (CNPq, Brazil), and Coordination for the Improvement of Higher Education Personnel (CAPES - Finance Code 001). The funding source had no involvement in the conduct of the research and/or preparation of the article.

\section{Conflict of Interest}

The authors declare that there is no conflict of interest regarding the publication of this paper.

\section{Author Contributions}

ACPF, JRIC, GMKC and PHC: conceived and the study; ACPF, BM, DDV and JFNN: conducted the experiments, ACPF, VMZ, VGR and PHC: analyzed the data, ACPF: wrote the manuscript; all authors read and approved the final version.

\section{References}

Castro MLD, Driemeyer J, Horvath C and Kops NL (2015) The role of fat mass and obesity associated gene (FTO) in satiety and binge eating disorder. Clin Biomed Res 35:178-183.

Church C, Moir L, McMurray F, Girard C, Banks GT, Teboul L, Wells S, Brüning JC, Nolan PM, Ashcroft FM et al. (2010) Overexpression of Fto leads to increased food intake and results in obesity. Nat Genet 42:1086-1092.

Dina C, Meyre D, Gallina S, Durand E, Körner A, Jacobson P, Carlsson LMS, Kiess W, Vatin V, Lecoeur C et al. (2007) Variation in FTO contributes to childhood obesity and severe adult obesity. Nat Genet 39:724-726.

Fonseca ACP, Ochioni AC, Silva Martins R, Zembrzuski VM, Campos Junior M, Ramos VG, Carneiro JRI, Nogueira Neto JF, Cabello PH and Cabello GMK (2017) Adiponectin, retinoic acid receptor responder 2 , and peroxisome proliferator-activated receptor- $\gamma$ coativator-1 genes and the risk for obesity. Dis Markers 2017:5289120.

Frayling TM, Timpson NJ, Weedon MN, Zeggini E, Freathy RM, Lindgren CM, Perry JRB, Elliott KS, Lango H and Rayner NW (2007) A common variant in the FTO gene is associated with body mass index and predisposes to childhood and adult obesity. Science 316:889-894.

Gerken T, Girard CA, Tung YL, Webby CJ, Saudek V, Hewitson KS, Yeo GSH, Mcdonough MA, Cunliffe S, Mcneill LA et al. (2007) The Obesity-Associated FTO gene encodes a 2-oxoglutarate-dependent nucleic acid demethylase. Science 318:1469-1472.

González JR, González-Carpio M, Hernández-Sáez R, Serrano Vargas V, Torres Hidalgo G, Rubio-Rodrigo M, GarcíaNogales A, Núñez Estévez M, Luengo Pérez LM and Rodríguez-López R (2012) FTO risk haplotype among early onset and severe obesity cases in a population of western Spain. Obesity (Silver Spring) 20:909-915.

Grundy SM (1998) Multifactorial causation of obesity: Implications for prevention. Am J Clin Nutr 67:563S-572S.

Hardy R, Wills AK, Wong A, Elks CE, Wareham NJ, Loos RJF, Kuh D and Ong KK (2010) Life course variations in the as- sociations between $F T O$ and $M C 4 R$ gene variants and body size. Hum Mol Genet 19:545-52.

Kitahara CM, Flint AJ, de Gonzalez AB, Bernstein L, Brotzman M, MacInnis RJ, Moore SC, Robien K, Rosenberg PS and Singh PN (2014) Association between class III obesity (BMI of $40-59 \mathrm{~kg} / \mathrm{m} 2$ ) and mortality: A pooled analysis of 20 prospective studies. PLoS Med 11:e1001673.

Lazopoulou N, Gioka E, Ntalla I, Pervanidou P, Magiakou A, Roma-Giannikou E, Chrousos GP, Papassotiriou I, Dedoussis $\mathrm{G}$ and Kanaka-Gantenbein C (2015) The combined effect of MC4R and FTO risk alleles on childhood obesity in Greece. Hormones 14:126-133.

Li H, Wu Y, Loos RJF and Lin X (2008) Variants in the Fat Mass - and Obesity-associated (FTO) gene are not associated with obesity in a Chinese Han population. Diabetes 57:264-268.

Loos RJF and Bouchard C (2008) FTO: The first gene contributing to common forms of human obesity. Obes Rev 9:246-50.

NCD Risk Factor Collaboration (2016) Trends in adult body-mass index in 200 countries from 1975 to 2014: A pooled analysis of 1698 population-based measurement studies with 19.2 million participants. Lancet 387:1377-1396.

Ohashi J, Naka I, Kimura R, Natsuhara K, Yamauchi T, Furusawa T, Nakazawa M, Ataka Y, Patarapotikul J, Nuchnoi P et al. (2007) FTO polymorphisms in oceanic populations. J Hum Genet 52:1031-1035.

Pereira PA, Alvim-Soares AM, Sandrim VC, Lanna CMM, Souza-Costa DC, Belo VA, Paula JJ, Tanus-Santos JE, Romano-Silva MA and de Miranda DM (2016) Lack of association between genetic polymorphism of FTO, AKT1 and AKTIP in childhood overweight and obesity. J Pediatr (Rio J) 92:521-527.

Prakash J, Mittal B, Srivastava A, Awasthi S and Srivastava N (2016) Association of FTO rs9939609 SNP with obesity and obesity-aAssociated phenotypes in a North Indian population. Oman Med J 31:99-106.

Price RA, Li WD and Zhao H (2008) FTO gene SNPs associated with extreme obesity in cases, controls and extremely discordant sister pairs. BMC Med Genet 9:1-5.

Ramos AV, Bastos-Rodrigues L, Resende BA, Friedman E, Campanha-Versiani L, Miranda DM, Sarquis M and De Marco L (2012) The contribution of FTO and UCP-1SNPs to extreme obesity, diabetes and cardiovascular risk in Brazilian individuals. BMC Med Genet 13:101.

Rankinen T, Zuberi A, Chagnon YC, Weisnagel SJ, Argyropoulos G, Walts B, Pérusse L and Bouchard C (2006) The human obesity gene map: The 2005 update. Obesity (Silver Spring) 14:529-644.

Reuter CP, Valim ARM, Gaya AR, Borges TS, Klinger EI, Possuelo LG, Franke SIR, Kmetzsch L, Vainstein MH, Prá D et al. (2016) FTO polymorphism, cardiorespiratory fitness, and obesity in Brazilian youth. Am J Hum Biol 28:381-386.

Rouskas K, Kouvatsi A, Paletas K, Papazoglou D, Tsapas A, Lobbens S, Vatin V, Durand E, Labrune Y, Delplanque J et al. (2012) Common variants in FTO, MC4R, TMEM18, PRL, AIF1, and PCSK1 show evidence of association with adult obesity in the Greek population. Obesity (Silver Spring) 20:389-95.

Scuteri A, Sanna S, Chen WM, Uda M, Albai G, Strait J, Najjar S, Nagaraja R, Orrú M, Usala G et al. (2007) Genome-wide as- 
sociation scan shows genetic variants in the FTO gene are associated with obesity-related traits. PLoS Genet 3:e115.

Sentinelli F, Incani M, Coccia F, Capoccia D, Cambuli VM, Romeo S, Cossu E, Cavallo MG, Leonetti F and Baroni MG (2012) Association of FTO polymorphisms with early age of obesity in obese Italian subjects. Exp Diabetes Res 2012:1-7.

Shabana and Hasnain S (2015) Effect of the common Fat Mass and Obesity Associated gene variants on obesity in Pakistani population: A case-control study. Biomed Res Int 2015:1-8.

Shabana, Ullah Shahid S, Wah Li K, Acharya J, Cooper JA, Hasnain S and Humphries SE (2016) Effect of six type II diabetes susceptibility loci and an FTO variant on obesity in Pakistani subjects. Eur J Hum Genet 24:903-910.

Smemo S, Tena JJ, Kim KH, Gamazon ER, Sakabe NJ, GómezMarín C, Aneas I, Credidio F, Sobreira D, Wasserman NF et al. (2014) Obesity-associated variants within FTO form long-range functional connections with IRX3. Nature 507:371.
Villalobos-Comparán M, Flores-Dorantes MT, Villarreal-Molina MT, Rodríguez-Cruz M, García-Ulloa AC, Robles L, Huertas-Vázquez A, Saucedo-Villarreal N, López-Alarcón M, Sánchez-Muñoz F et al. (2008) The FTO gene is associated with adulthood obesity in the Mexican population. Obesity (Silver Spring) 16:2296-301.

Wu Y, Duan H, Tian X, Xu C, Wang W, Jiang W, Pang Z, Zhang D and Tan Q (2018) Genetics of obesity traits: A bivariate genome-wide association analysis. Frontiers Genet 9:179.

Zar JH (1999) Biostatistical Analysis. 4th edition. Prentice-Hall, New Jersey.

\section{Internet Resources}

WHO - World Health Organization, http://www.who.int/mediacentre/factsheets/fs311/en/ (accessed 22 August 2018).

Associate Editor: Regina C. Mingroni-Netto

License information: This is an open-access article distributed under the terms of the Creative Commons Attribution License (type CC-BY), which permits unrestricted use, distribution and reproduction in any medium, provided the original article is properly cited. 